Article

\title{
First-Principles Studies on the Structural and Electronic Properties of As Clusters
}

\author{
Jialin Yan ${ }^{1,2,3}$, Jingjing Xia ${ }^{2}$, Qinfang Zhang ${ }^{1, *(1)}$, Binwen Zhang ${ }^{1}$ and Baolin Wang ${ }^{3, *}$ \\ 1 School of Materials Science and Engineering, Yancheng Institute of Technology, Yancheng 224051, China; \\ yanjl@ycit.edu.cn (J.Y.); zhangbw@ycit.edu.cn (B.Z.) \\ 2 College of Education Science, Nantong University, Nantong 226019, China; xiajj@ycit.edu.cn \\ 3 School of Physical Science and Technology, Nanjing Normal University, Nanjing 210023, China \\ * Correspondence: qfangzhang@ycit.edu.cn (Q.Z.); wangbl@ycit.edu.cn (B.W.); Tel.: +86-515-8829-8250 (Q.Z.)
}

Received: 10 August 2018; Accepted: 31 August 2018; Published: 3 September 2018

\begin{abstract}
Based on the genetic algorithm (GA) incorporated with density functional theory (DFT) calculations, the structural and electronic properties of neutral and charged arsenic clusters $\mathrm{As}_{\mathrm{n}}(n=2-24)$ are investigated. The size-dependent physical properties of neutral clusters, such as the binding energy, HOMO-LUMO gap, and second difference of cluster energies, are discussed. The supercluster structures based on the $\mathrm{As}_{8}$ unit and $\mathrm{As}_{2}$ bridge are found to be dominant for the larger cluster $\mathrm{As}_{\mathrm{n}}(n \geq 8)$. Furthermore, the possible geometric structures of $\mathrm{As}_{28}, \mathrm{As}_{38}$, and $\mathrm{As}_{180}$ are predicted based on the growth pattern.
\end{abstract}

Keywords: atomic clusters; density functional theory; genetic algorithm

\section{Introduction}

In recent years, due to the fast development of nanotechnology, people are more interested in atomic clusters, which are composed of several to thousands of atoms, molecules, or ions through a physical or chemical bonding force [1]. Clusters can also be regarded as the transitional forms between atoms and bulk, and their fundamental properties depend vitally on the cluster size. Therefore, it is quite meaningful to study the structural and electronic properties of clusters using theoretical research, identifying their potential capacities for numerous applications. Arsenic has been widely applied in many fields such as semiconductors, optoelectronics, and biopharmaceutics [2-11]. Besides, vanadium doped phosphorus clusters, and pure and doped arsenic clusters have received a large amount of attention from both experimental and theoretical fields in recent years [12-23].

Experimentally, the study of As $s_{n}$ clusters has focused on small-sized clusters with $n \leq 5$ [12-17]. For example, Wang et al. [12] utilized high-resolution photoelectron spectroscopy to study the electronic vibration and spin orbit of $\mathrm{As}_{4}$. Bennett et al. [13] have measured the appearance potentials and ion translational energies for the $\mathrm{As}_{1}, \mathrm{As}_{2}$, and $\mathrm{As}_{3}$ ions formed by the dissociative resonance capture of $\mathrm{As}_{4}$. Lippa et al. [14] have probed the electron affinities of $A s_{n}(n=1-5)$ using photoelectron spectra in 1998. Brumbach and Rosenblatt [15] have investigated the vibrational modes of As 4 with Raman spectroscopy. Yonezo [16] designed a high-temperature nozzle assembly for gas-electron diffraction to determine the structure of $\mathrm{As}_{4}$. Jeffrey et al. [17] measured the ionization potentials (IPs) for $\operatorname{As}_{n}(n=1-5)$ using gas-phase charge-transfer reactions. No experimental data are available for $\mathrm{As}_{\mathrm{n}}$ with $n \geq 6$ right now.

In the theoretical aspect, Zhao et al. [18] and Bai et al. [21] studied the structures, thermochemistry, and electron affinities of $A s_{n}(n=1-16)$ and their anions. Their results showed that the even-numbered neutral $A s_{n}$ species are more stable than the odd-numbered clusters, but the even-numbered anionic $\mathrm{As}_{\mathrm{n}}$ species are less stable than the odd-numbered species. Liang et al. [19] probed the 
electronic structure and property of neutral and charged arsenic clusters $\operatorname{As}_{\mathrm{n}}{ }^{(+1,0,-1)}(n=2-8)$. At the B3LYP/6-311+G(d) theoretical level, Guo [20] investigated the geometries and energies for neutral and charged $\mathrm{As}_{\mathrm{n}}(n=2-15)$ clusters, and reported their relative stability, ionization potential, and electron affinity. Baruah et al. [23] using a generalized gradient approximation (GGA) to explore the geometry, vibrational modes, and polarizabilities, as well as the infrared and Raman spectra of fullerene-like arsenic cages with $n=4,8,20,28,32,36$, and 60. Zhao et al. [22] investigated the structures and electronic properties of $A s_{n}$ clusters with even-numbered $A_{n}(n=6-28)$ using density functional theory (DFT) with the Perdew-Burke-Ernzerhof functional and a doubled numerical basis set with d-polarization functions(PBE/DND) scheme and found that the supercluster structures based on $\mathrm{As}_{4}$, $\mathrm{As}_{6}$, and $\mathrm{As}_{8}$ units, and the $\mathrm{As}_{2}$ bridge were dominant for the larger $\mathrm{As}_{\mathrm{n}}$ with $n \geq 14$.

Although many theoretical works have been performed on the As $s_{n}$ clusters, all the results are always most of the artificial speculation studies to investigate the structure of clusters in certain symmetries. In this work, we have performed a genetic algorithm (GA) incorporated with density functional theory (DFT) calculations to explore the structures and electronic properties of $\mathrm{As}_{n}(n=2-24)$ neutral and charged clusters. After we have determined the growth pattern of $\mathrm{As}_{\mathrm{n}}$ clusters, the possible geometric structures of $\mathrm{As}_{28}, \mathrm{As}_{38}$, and $\mathrm{As}_{180}$ are predicted based on the growth pattern. We also discussed the size-dependent physical properties of neutral clusters such as the binding energy, HOMO-LUMO gap and second difference of cluster energies.

\section{Computational Methodology}

In order to search the global minimum structures of $A s_{n}$ clusters, we combined a genetic algorithm (GA) simulation with local optimization at the $\mathrm{Dmol}^{3}$ level [24-29]. The fundamental aim in GA is to divide the potential-energy surface (PES) into a number of regions and find the locally stable isomers in each region. In the GA program, we generated $15 \mathrm{As}_{\mathrm{n}}(n=3-12)$ and $20 \mathrm{As}_{\mathrm{n}}(n=13-24)$ initial populations to ensure that we could find the local minimum. Any population can be chosen as parents to generate their child cluster according to a crossover operation. In addition, there was a possibility of a 30\% mutation rate for a single parent to produce child alone. The child cluster was optimized with $\mathrm{Dmol}^{3}$, and then compared with its parent in energy. The child with lower energy replaced its high-energy parent. The whole process of genetic algorithm with 2000 iterations was to ensure we got the lowest energy structure.

The optimization of $\mathrm{As}_{\mathrm{n}}(n=2-24)$ clusters was performed using DFT with the PerdewBurke-Ernzerhof (PBE) [24] exchange-correlation functional and an all-electron basis set of the double-numerical-plus-d-polarization (DND) type, as implemented in the $\mathrm{Dmol}^{3}$ [25] package. A self-consistent field calculation kept the accuracy with an energy convergence for $10^{-6}$ a.u., and the forces for $2 \times 10^{-3}$ a.u. There was no symmetry restriction for geometry optimization.

For each $\operatorname{As}_{n}(n=2-24)$ cluster, we saved ten energetically lower isomer structures for further electronic structure calculations, which were performed using the Vienna Ab-initio Simulation Package (VASP) codes. The Kohn-Sham equations were solved variationally in a plane wave basis set using the projector-augmented-wave (PAW) method. The exchange-correlation energy was described by the functional of Perdew, Burke, and Ernzerhof (PBE) based on the generalized gradient approximation (GGA). The energy cutoff was set to be $400 \mathrm{eV}$ and the vacuum space was set to be at least $14 \AA$ to separate the interactions between the neighboring slabs. Only the Gamma k-point was used to sample the Brillouin zone for the geometry and electronic structure calculations. All structures were fully relaxed by Gaussian smearing and electronic structure calculations by tetrahedron smearing method until the convergence criteria (with the force less than $0.02 \mathrm{eV} / \AA$ and the energy less than $\left.10^{-5} \mathrm{eV}\right)$. Although each structure of $\operatorname{As}_{\mathrm{n}}(n=2-24)$ cluster was further optimized by VASP, the energy sequencing of each cluster was basically unchanged. 


\section{Results and Discussions}

\section{1. $A s_{n}(n=2-8)$ Clusters}

The bond length of an $\mathrm{As}_{2}$ cluster (2a in Figure 1) is $2.103 \AA$ through experimental measurement [30]. In our calculation the distance between the As atoms was $2.118 \AA$, which is closer to the experimental data compared with the $2.142 \AA$ calculated using PBE/DND methods [22].

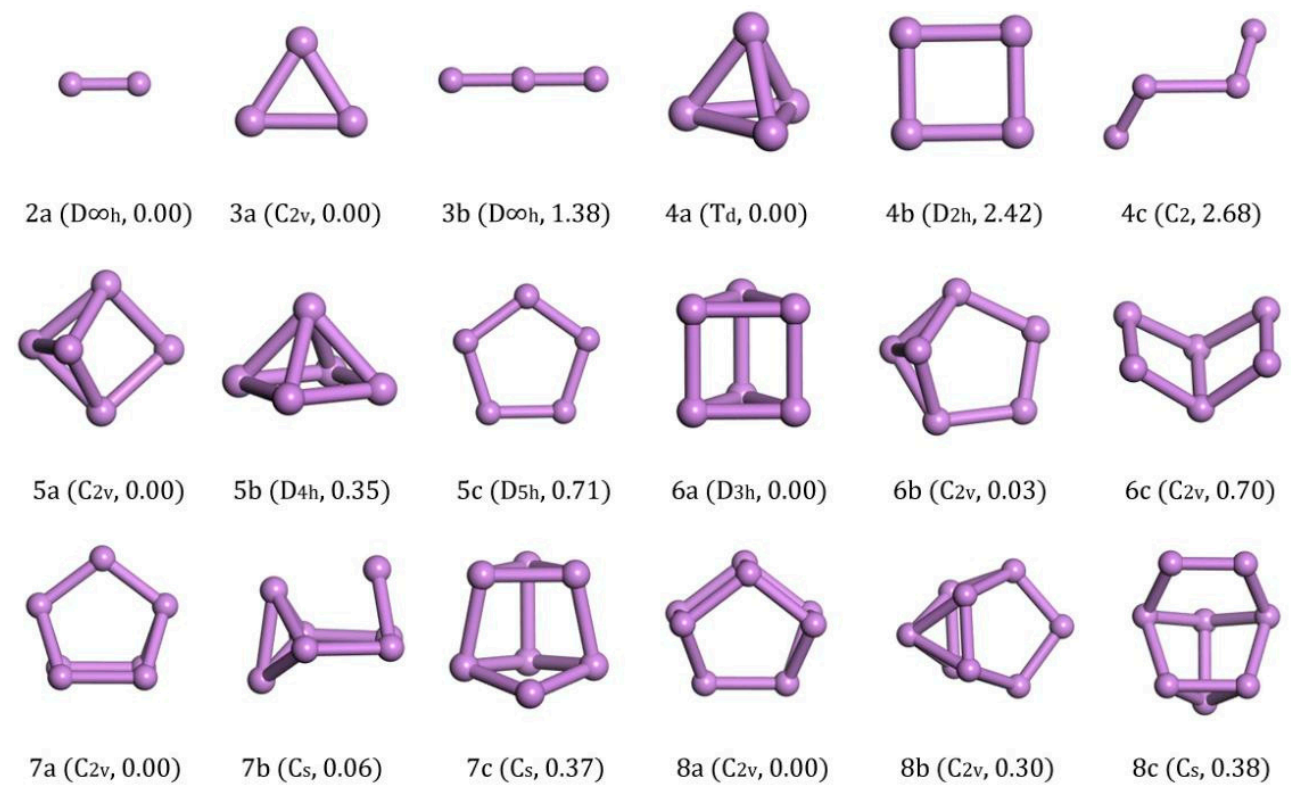

Figure 1. Lowest-energy and isomorphic structures for $\mathrm{As}_{n}(n=2-8)$ clusters. The relative total energies are in $\mathrm{eV}$.

For the $\mathrm{As}_{3}$ cluster, the energy of the structure with $\mathrm{C}_{2 \mathrm{v}}$ symmetry (3a in Figure 1) was the global minimum. It was an isosceles triangle structure with a top angle of $65.14^{\circ}$ and side length of $2.325 \AA$. It was energetically lower than the linear chain structure with Doh symmetry ( $3 b$ in Figure 1), in which structure, the bond length was $2.204 \AA$.

The ground-state structure of $\mathrm{As}_{4}$ with $\mathrm{T}_{\mathrm{d}}$ symmetry (4a in Figure 1) was a regular tetrahedron, which was consistent with the previous reports [18-20]. Its energy was much lower than other isomorphic configurations. The energy of the rectangular structure with $\mathrm{D}_{2 \mathrm{~h}}$ symmetry $(4 \mathrm{~b}$ in Figure 1$)$ was $0.605 \mathrm{eV}$ /atom higher than that of the ground state and the chain structure with $\mathrm{C}_{2}$ symmetry (4c in Figure 1) was energetically higher than the rectangular structure.

The lowest energy structure of $\mathrm{As}_{5}$ had $\mathrm{C}_{2 \mathrm{v}}$ symmetry (5a in Figure 1 ) and it may be considered as adding an atom in the cross section of a dihedral formed by four atoms. It had $0.07 \mathrm{eV} /$ atom less energy than the rectangular pyramid structure with $\mathrm{D}_{4 \mathrm{~h}}$ symmetry ( $5 \mathrm{~b}$ in Figure 1 ) and $0.142 \mathrm{eV} /$ atom less than the planar structure with $\mathrm{D}_{5 \mathrm{~h}}$ symmetry (5c in Figure 1).

The trigonal prism with $\mathrm{D}_{3 \mathrm{~h}}$ symmetry (6a in Figure 1) was the ground-state structure for $\mathrm{As}_{6}$ and was only $0.005 \mathrm{eV} /$ atom lower than the benzvalene type with $\mathrm{C}_{2 \mathrm{v}}$ symmetry ( $6 \mathrm{~b}$ in Figure 1 ) and $0.117 \mathrm{eV} /$ atom lower than the dihedral angle structure of six atoms with $\mathrm{C}_{2 \mathrm{v}}$ symmetry (6c in Figure 1). The side length was $2.522 \AA$ and the edge length was $2.559 \AA$. Our ground state was consistent with the result calculated by B3LYP/6-311+G(d) [20] or PBE/DND methods [22]. However, the structure $6 \mathrm{~b}$ in Figure 1 was found to be the lowest energy by Liang [19] using MP2(full)/g-31G(d) methods and Bai [21] using B3LYP/DZP++ methods. As the outer shell structure of As is $3 s^{2} 3 p^{3}$, we think our results are reasonable as the completely three-coordination structure (6a in Figure 1) must be more stable than the structure with two two-coordinations ( $6 \mathrm{~b}$ in Figure 1). 
In the case of $\mathrm{As}_{7}$, the ground-state structure with $\mathrm{C}_{2} \mathrm{v}$ symmetry (7a in Figure 1 ) could be derived from the trigonal prism of $\mathrm{As}_{6}$ by edge-capping with an additional As atom. This low-energy structure is also predicted in Refs. [19-21]. Its energy was lower than the structure with Cs symmetry (7b in Figure 1) by $0.008 \mathrm{eV} /$ atom and the structure with Cs symmetry (7c in Figure 1) by $0.053 \mathrm{eV} /$ atom.

The wedge-like structure that looks like a cage with $\mathrm{C}_{2 \mathrm{v}}$ symmetry was obtained as the lowest energy structure for $\mathrm{As}_{8}$, as seen from $8 \mathrm{a}$ in Figure 1. It was energetically lower than the structure with $\mathrm{C}_{2 \mathrm{v}}$ symmetry ( $8 \mathrm{~b}$ in Figure 1) by $0.038 \mathrm{eV} /$ atom and the structure with Cs symmetry (8c in Figure 1) by $0.048 \mathrm{eV} /$ atom. We also checked the cage structure with $\mathrm{O}_{\mathrm{h}}$ symmetry cut from the bulk phase reported by Baruah [23], and we found that it was $0.64 \mathrm{eV}$ energy higher than our ground state structure.

After analysis of the ground structures of $\mathrm{As}_{\mathrm{n}}(n=2-8)$ clusters, we find that $\mathrm{As}_{2}$ was a one-dimensional bridge, $\mathrm{As}_{3}$ was a two-dimensional isosceles triangle and $\mathrm{As}_{4}$ became a three-dimensional tetrahedron. When $n$ was larger than 3 , the two-dimensional cluster structure, such as $4 \mathrm{~b}$ and $5 \mathrm{c}$ in Figure 1, sorts more and more backward energetically. We can conclude that the structure of small As clusters tends towards a three-dimensional cage structure and it was not stable for a 2-D planar structure.

\section{2. $A s_{n}(n=9-18)$ Clusters}

The ground-state structure of $\mathrm{As}_{9}$ with $\mathrm{C}_{\mathrm{s}}$ symmetry (9a in Figure 2) could be regarded as being derived from a cage-like $\mathrm{As}_{8}$ structure by attaching an As atom at one side. The isomers $\left(\mathrm{C}_{2 \mathrm{v}}\right)$ with a higher symmetry (9b,c in Figure 2) were less stable based on our VASP calculations. It also hinted to us that the ground structure of $\mathrm{As}_{8}$ might be a stable cluster with a magic number. From further calculations, we found that the cage-like $\mathrm{As}_{8}$ structures unit served as the primary building unit for forming the As clusters with larger sizes.

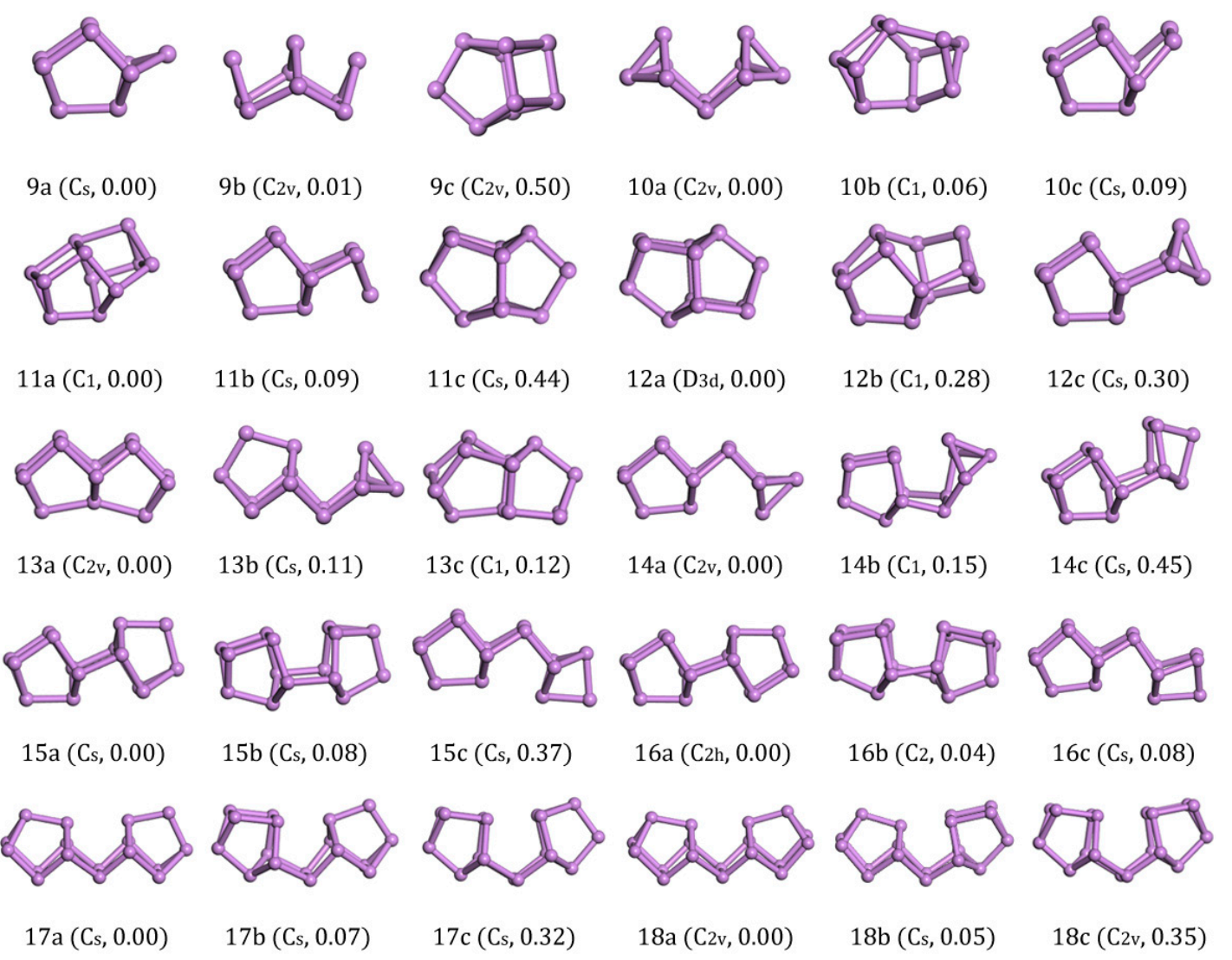

Figure 2. Lowest-energy and isomorphic structures for $\mathrm{As}_{\mathrm{n}}(n=9-18)$ clusters. The relative total energies are in $\mathrm{eV}$. 
The lowest-energy structure $\left(\mathrm{C}_{2 \mathrm{v}}\right)$ of $\mathrm{As}_{10}$ consistd of the cage structure of $8 \mathrm{a}$ in Figure 1 that was edge-capped by each As atom. After relaxation, the upper bond broke to form two four-atom cages and an $\mathrm{As}_{2}$ bridge. The structure 10b in Figure 2 was a new structure discovered by our GA global searching. The structure obtained by Zhao [22] is structure 10c in Figure 2, whose energy was higher than $10 \mathrm{~b}$ in Figure 2 by $0.006 \mathrm{eV} /$ atom and 10a in Figure 2 by $0.009 \mathrm{eV} /$ atom.

The ground structure of $A s_{11}$ was 11a in Figure 2 which was formed on the base of $\mathrm{As}_{10}$ with an As atom added above the $\mathrm{As}_{2}$ dimer and linked with an $\mathrm{As} \mathrm{s}_{8}$ cage. It was more stable than the $11 \mathrm{~b}$ in Figure 2 isomer with $C_{s}$ symmetry by $0.008 \mathrm{eV} /$ atom and 11c in Figure 2 isomer by $0.04 \mathrm{eV} /$ atom with $\mathrm{C}_{\mathrm{s}}$ symmetry in energy.

For $\mathrm{As}_{12}$, the structure with $\mathrm{D}_{3 \mathrm{~d}}$ symmetry was confirmed to be the lowest energy structure among all the structural candidates considered. The highly-symmetric structure was shaped of two $\mathrm{As}_{8}$ cages that share a four-atom plane. From another point of view, the ground-state structure of $\mathrm{As}_{12}$ was a layered structure of three layers of atoms $(3+6+3)$. Such a nice structure was energetically lower than $12 \mathrm{~b}$ in Figure 2 with $C_{1}$ symmetry by $0.023 \mathrm{eV} /$ atom and $12 \mathrm{c}$ in Figure 2 with $\mathrm{C}_{\mathrm{s}}$ symmetry by $0.025 \mathrm{eV} /$ atom.

Viewing the ground-state structure of $\mathrm{As}_{13}$ carefully, we also found two As 8 cages. Different from $\mathrm{As}_{12}$, the two cages jointly owned a three-atom plane. It had $0.008 \mathrm{eV} /$ atom less energy than the structural $13 \mathrm{~b}$ in Figure $2\left(C_{1}\right)$ and $0.009 \mathrm{eV} /$ atom less than the structure $13 \mathrm{c}$ in Figure $2\left(C_{\mathrm{s}}\right)$.

As shown in the picture, $\mathrm{As}_{14}$ with $\mathrm{Cs}$ symmetry could be considered to be composed of an As atom link to the three-atom plane on one side of the $\mathrm{As}_{13}$ (13a in Figure 2). The less stable isomer $14 \mathrm{~b}$ was a distorted structure of $14 \mathrm{a}$, which was energetically higher by $0.011 \mathrm{eV} / \mathrm{atom}$. The $14 \mathrm{c}$ was a structure without an $\mathrm{As}_{2}$ dimer bridge, it was linked by $\mathrm{As}_{8}$ cage with an $\mathrm{As}_{6}$ cage and had $0.032 \mathrm{eV} /$ atom more energy than 14a in Figure 2.

The ground-state structure of $\mathrm{As}_{15}$ with $\mathrm{C}_{\mathrm{s}}$ symmetry was composed of two connected cages (As8 and $\mathrm{As}_{7}$ ). The other two candidates $15 \mathrm{~b}$ in Figure 2 with $\mathrm{C}_{\mathrm{s}}$ symmetry and $15 \mathrm{c}$ in Figure 2 with $\mathrm{C}_{\mathrm{s}}$ symmetry were less stable than the ground-state structure by $0.005 \mathrm{eV} /$ atom and $0.025 \mathrm{eV} /$ atom in energy, respectively.

An upward $\mathrm{As}_{8}$ cage and a downward $\mathrm{As}_{8}$ cage connected to form a new structure as the ground state of $\mathrm{As}_{16}$ (16a in Figure 2 with $\mathrm{C}_{2 \mathrm{~h}}$ symmetry). It was more stable than the $\mathrm{C}_{2}$-symmetry isomer $16 \mathrm{~b}$ in Figure 2 and the $\mathrm{C}_{\mathrm{s}}$-symmetry isomer 16c in Figure 2 by $0.05 \mathrm{eV}$ and $0.08 \mathrm{eV}$ in energy. Although structural 16c in Figure 2 contained an $\mathrm{As}_{8}$ cage and an $\mathrm{As}_{2}$ bridge, the $\mathrm{As}_{6}$ cage in the structure led to the overall energy as being higher than other two isomers.

The lowest energy structure of $\mathrm{As}_{17}$ (17a in Figure 2) with $\mathrm{C}_{\mathrm{s}}$ symmetry was built by $\mathrm{As}_{8}$ and $\mathrm{As}_{7}$ units with an $\mathrm{As}_{2}$ bridge in the middle. The two $\mathrm{C}_{\mathrm{s}}$-symmetry isomorphic structure $17 \mathrm{~b}, \mathrm{c}$ in Figure 2 were also formed by the $\mathrm{As}_{8}$ and $\mathrm{As} \mathrm{s}_{7}$ units with different orientation connections.

The ground-state of $\mathrm{As}_{18}$ (18a in Figure 2) with $\mathrm{C}_{2 \mathrm{v}}$ symmetry was formed by two identical $\mathrm{As}_{8}$ units and an $\mathrm{As}_{2}$ bridge in the middle. Our structure was exactly the same as that in Ref. [22]. Two slightly higher energy isomers (18b in Figure 2) with $C_{2 h}$ symmetry and $18 \mathrm{c}$ in Figure 2 with $C_{2 v}$ symmetry were combined by the same units as 18a in Figure 2 with different orientations, and they were energetically higher than 18a in Figure 2 by $0.05 \mathrm{eV}$ and $0.35 \mathrm{eV}$ energy. The calculations showed that the structure with $\mathrm{As}_{8}$ unit and $\mathrm{As}_{2}$ bridge in the middle was more stable than other cage structures. We also generated one $\mathrm{As}_{18}$ structure cut from bulk phase and the energy was $3.17 \mathrm{eV}$ higher than the ground state. So, we think the chain structure with $\mathrm{As}_{8}$ units and an $\mathrm{As}_{2}$ bridge is much more important for middle-sized $\mathrm{As}_{\mathrm{n}}$ clusters.

\section{3. $A s_{n}(n=19-24)$ Clusters}

The ground-state structure of $\mathrm{As}_{19}$ (19a in Figure 3) with $\mathrm{C}_{\mathrm{s}}$ symmetry could be regarded as an As atom added into one side of $\mathrm{As}_{18}$. Therefore, $\mathrm{As}_{19}$ (19a in Figure 3) could be considered as the combination of $\mathrm{As}_{8}-\mathrm{As}_{2}-\mathrm{As}_{8}-\mathrm{As}_{1}$. The isomers of $\mathrm{As}_{19}$ (19b,c in Figure 3) with only $\mathrm{C}_{1}$ symmetry were 
both built up by two identical $\mathrm{As}_{8}$ units and an $\mathrm{As}_{3}$ bridge. Due to the distortion of the structures, they had $0.008 \mathrm{eV} /$ atom and $0.009 \mathrm{eV} /$ atom higher energy than 19a in Figure 3.

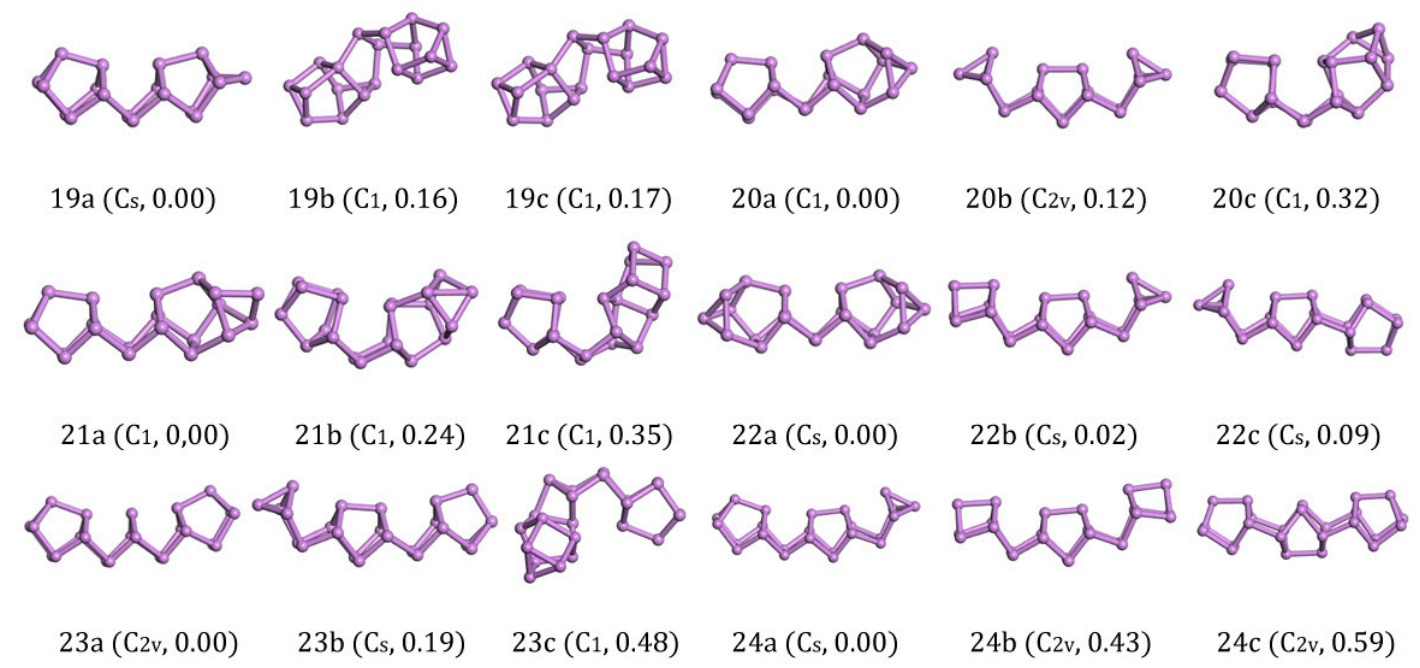

Figure 3. Lowest-energy and isomorphic structures for $\mathrm{As}_{\mathrm{n}}(n=19-24)$ clusters. The relative total energies are in $\mathrm{eV}$.

The ground-state structures of $\mathrm{As}_{20}$ was predicted to be $\mathrm{C}_{1}$ symmetry, as shown in 20a in Figure 3. It could be regarded as an $\mathrm{As}_{8}$ cage link with an $\mathrm{As}_{10}$ cage joined by an $\mathrm{As}_{2}$ bridge. $\mathrm{As} \mathrm{s}_{20}$ (20a in Figure 3 ) could be considered as the combination of $\mathrm{As}_{8}-\mathrm{As}_{2}-\mathrm{As}_{10}$. Zhao [22] predicted the optimal combinations for the $\mathrm{As}_{20}$ is super-clusters of $\mathrm{As}_{4}-\mathrm{As}_{2}-\mathrm{As}_{8}-\mathrm{As}_{2}-\mathrm{As}_{4}$. The energy of $\mathrm{As}_{20}$ (20a in Figure 3) we got based on the genetic algorithm was energetically lower than the structure $20 \mathrm{~b}$ in Figure 3 with $C_{2 v}$ symmetry. A distorted structure 20c in Figure 3 originated from 20a in Figure 3 also appeared in our calculations. After the calculations with VASP, two isomers showed $0.006 \mathrm{eV} /$ atom and $0.053 \mathrm{eV} /$ atom higher energy than 20a in Figure 3. This result shows the super-clusters of $\mathrm{As}_{4}-\mathrm{As}_{2}-\mathrm{As}_{8}-\mathrm{As}_{2}-\mathrm{As}_{4}$ did not have much of an advantage.

For $\mathrm{As}_{21}$, the most stable structure (21a in Figure 3) could be regarded as an As atom link to the $A s_{10}$ cage of $A s_{20}$ (20a in Figure 3). Two other isomers (21b,c in Figure 3) were constituted by an $A s_{8}$ cage and an irregular $\mathrm{As}_{11}$ structure linked with an $\mathrm{As}_{2}$ bridge. They were energetically higher than 21a in Figure 3 by $0.011 \mathrm{eV} /$ atom and $0.017 \mathrm{eV} /$ atom.

Rather than simply increasing the number of atoms on the edge, the ground-state structure of $\mathrm{As}_{22}$ with $\mathrm{C}_{\mathrm{s}}$ symmetry are formed with two symmetrical $\mathrm{As}_{10}$ cages in the $\mathrm{As}_{20}$ units and an $\mathrm{As}_{2}$ bridge in the middle. The isomers were two kinds of super-clusters (22b in Figure 3, $\mathrm{As}_{6}-\mathrm{As}_{2}-\mathrm{As}_{8}-\mathrm{As}_{2}-\mathrm{As}_{4}$ and 22c in Figure 3, $\mathrm{As}_{4}-\mathrm{As}_{2}-\mathrm{As}_{8}-\mathrm{As}_{8}$ ), and they were stretched by more units compared to the ground-state structures (22a in Figure 3). Although we could find stable $\mathrm{As}_{8}$ and $\mathrm{As}_{4}$ units in isomers, they each had $0.02 \mathrm{eV}$ and $0.09 \mathrm{eV}$ higher energy than 22a in Figure 3. According to previous findings, it can be found that the second lower energy $\mathrm{As}_{10}$ cage 10b in Figure 2 will be favorable if the structure is composed by an $\mathrm{As}_{8}$ unit connected with an $\mathrm{As}_{2}$ bridge.

The ground-state structures of $\mathrm{As}_{23}$ (23a in Figure 3) with $\mathrm{C}_{2 \mathrm{v}}$ symmetry seemed to be four $\mathrm{As}_{8}$ cages linked to each other to share the three-atom plane, and the bottom edge of the middle two cages were broken. At the same time, we could also regard 23a in Figure 3 as a super-cluster of $\mathrm{As}_{8}-\mathrm{As}_{2}-\mathrm{As}_{3}-\mathrm{As}_{2}-\mathrm{As}_{8}$. The other two candidates, $23 \mathrm{~b}$ in Figure 3 with $\mathrm{C}_{\mathrm{s}}$ symmetry and $23 \mathrm{c}$ in Figure 3 with $C_{1}$ symmetry, were less stable than the structure 23a in Figure 3 by $0.008 \mathrm{eV} /$ atom and $0.021 \mathrm{eV} /$ atom in energy, respectively.

The lowest energy structure of $\mathrm{As}_{24}$ with $\mathrm{C}_{\mathrm{s}}$ symmetry (24a in Figure 3) was built by three units (an $\mathrm{As}_{4}$ cage and two identical As 8 cages), connecting the neighboring structure with an $\mathrm{As}_{2}$ bridge. Zhao [22] considered that the optimal combinations of the super-clusters $\mathrm{As}_{24}$ are $\mathrm{As}_{6}-\mathrm{As}_{2}-\mathrm{As}_{8}-\mathrm{As}_{2}-\mathrm{As}_{6}$ 
(24b in Figure 3) with $C_{2 v}$ symmetry. DFT calculations show that the ground-state structure of $\mathrm{As}_{24}$ we get based on the genetic algorithm weare the combinations of $\mathrm{As}_{8}-\mathrm{As}_{2}-\mathrm{As}_{8}-\mathrm{As}_{2}-\mathrm{As}_{4}$, which was energetically lower than the structure $24 \mathrm{~b}$ in Figure 3 by $0.018 \mathrm{eV} /$ atom. Besides, we also gained another high symmetric structure with $\mathrm{C}_{2 \mathrm{v}}$ symmetry (24c in Figure 3 ) that was constituted by three $\mathrm{As}_{8}$ units. However, its energy was $0.025 \mathrm{eV} /$ atom higher than the ground state structure $(24 \mathrm{a}$ in Figure 3). We could realize from this result that the lowest energy structures of larger As clusters not only have the combination of $\mathrm{As}_{8}$ units but also needed an $\mathrm{As}_{2}$ bridge in the middle of adjacent units.

\section{4. $A s_{n}(n=2-24)$ Charged Clusters}

We also studied the ground structures of $\operatorname{As}_{n}(n=2-24)$ charged clusters. Theoretically, it was easy to simulate a cationic or anionic cluster by adjusting the total electrons from the neutral cluster. From Figures S2 and S3, we could know the lowest energy structures of charged clusters $(n=2-4)$ were almost the same as with neutral cases. For As 8 clusters, 8 a in Figure 1 structures were quite stable even in cationic or anionic cases and it was the cluster with the magic number. For other $\operatorname{As}_{n}(n<16)$ clusters, the isomers changed the energy sequence as the system changed the electron numbers. It was interesting to find that the structures for $\operatorname{As}_{n}(15<n<24)$ clusters were quite stable whatever attachment of extra electron to the neutral or losing of an electron from the neutral cluster.

\section{5. $A s_{n}(n=28,38,40,180)$ Clusters}

With the increase of cluster size, it was more and more difficult to exhaust all possible local minimum structures. We tried to study the larger clusters $\mathrm{As}_{28}, \mathrm{As}_{38}$, and $\mathrm{As}_{40}$ based on the above findings. The structural size evolution and electronic properties of arsenic clusters indicated that the clusters combined by an $\mathrm{As}_{2}$ bridge and an $\mathrm{As}_{8}$ cage had lower energy than their isomers and showed more stability in each local size-dependent range. Here we have to emphasize that $\mathrm{As}_{4}$ and $\mathrm{As}_{6}$ units were not dominant for the larger $\mathrm{As}_{\mathrm{n}}$ cluster, which was different from Zhao's result [22]. Furthermore, different sizes of fullerene cage structure isomers were also calculated to compare with our ground state structures in energy, and their energies were far more than units-linked one-dimensional structures. Given this understanding, we constructed $\mathrm{As}_{28}$ as $\mathrm{As}_{8}-\mathrm{As}_{2}-\mathrm{As}_{8}-\mathrm{As}_{2}-\mathrm{As}_{8}$ and $\mathrm{As}_{38}$ as $\mathrm{As}_{8}-\mathrm{As}_{2}-\mathrm{As}_{8}-\mathrm{As}_{2}-\mathrm{As}_{8}-\mathrm{As}_{2}-\mathrm{As}_{8}$ in all possible ways. The structures we calculated of $\mathrm{As}_{28}$ are listed along with the increase of energy in Figure 4. The lowest energy structure of $\mathrm{As}_{28}$ with $\mathrm{C}_{2 \mathrm{v}}$ symmetry (Figure $4 \mathrm{a}$ ) had $0.05 \mathrm{eV}$ less energy than the structure with $\mathrm{C}_{\mathrm{s}}$ symmetry (Figure $4 \mathrm{~b}$ ) and $0.10 \mathrm{eV}$ less than the structure with $\mathrm{C}_{2 \mathrm{v}}$ symmetry (Figure $4 \mathrm{c}$ ). In addition to considering structure growth in the one-dimensional direction, we also calculated the longitudinal growth mode. Three isomers Figure $4 \mathrm{c}, \mathrm{e}, \mathrm{f}$ were all with $\mathrm{C}_{\mathrm{s}}$ symmetry and energetically higher than the lowest energy structure a with $0.08 \mathrm{eV}, 0.35 \mathrm{eV}$, and $0.40 \mathrm{eV}$, respectively. Besides, the other two semi-ring isomers Figure 4g, $\mathrm{h}$ had $0.44 \mathrm{eV}$ and $0.70 \mathrm{eV}$ energy higher than the ground state structure. Compared with the bulk truncated structure of $\mathrm{As}_{28}$, the lowest energy structure of $\mathrm{As}_{28}$ was $0.16 \mathrm{eV} /$ atom lower.

The lowest energy structure of $\mathrm{As}_{38}$ with $\mathrm{C}_{2 \mathrm{v}}$ symmetry (Figure $5 \mathrm{a}$ ) and its isomers are listed in Figure 5. We could find that the structure of Figure 5a was a continuation of $\mathrm{As}_{8}, \mathrm{As}_{18}$, and $\mathrm{As}_{28}$ clusters, and all of them were constructed with $\mathrm{As}_{8}$ cages in the same direction with $\mathrm{As}_{2}$ bridges. The structural isomers Figure $5 b$ with $C_{2 v}$ symmetry and Figure $5 c$ with $C_{2 h}$ symmetry could be regarded as one-dimensional chain structures, the same as Figure 5a. Their respective energies were $0.10 \mathrm{eV}$ and $0.22 \mathrm{eV}$ higher than Figure $5 \mathrm{a}$. The $C_{2 \mathrm{v}}$ isomer Figure $5 \mathrm{~d}$ could be regarded as a two-dimensional structure that has four $\mathrm{As}_{8}$ cages held in four directions and all of them point to the center. The energy of this structure was highest in our calculation with $1.11 \mathrm{eV}$ higher energy than a. Compared with the bulk truncated structure of $\mathrm{As}_{38}$, the lowest energy structure of $\mathrm{As}_{38}$ was $0.156 \mathrm{eV} /$ atom lower. We could find that the structures did not change previous growth tendencies even with increasing the size of the clusters. 


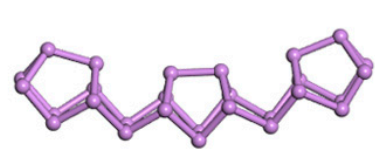

$\mathrm{a}(\mathrm{C} 2 \mathrm{v}, 0.00)$

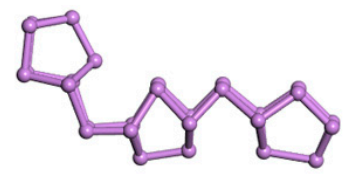

c (Cs, 0.08)

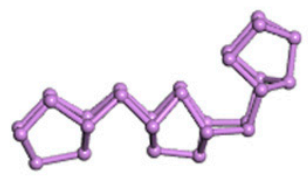

e (Cs, 0.35)

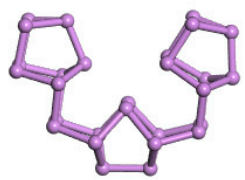

g (Cs, 0.44)

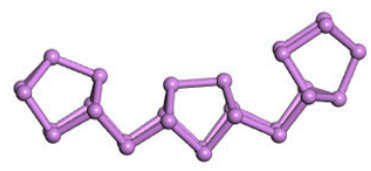

b (Cs, 0.05)

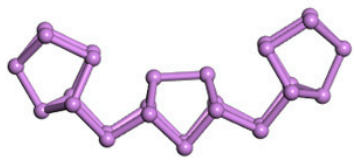

$\mathrm{d}(\mathrm{C} 2 \mathrm{v}, 0.10)$

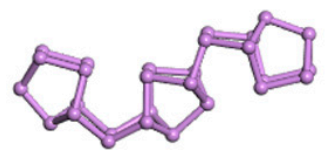

$\mathrm{f}(\mathrm{Cs}, 0.40)$

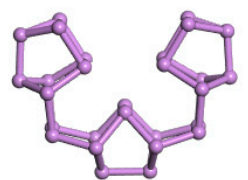

h $(\mathrm{C} 2 \mathrm{v}, 0.70)$

Figure 4. Lowest-energy and isomorphic structures for $\mathrm{As}_{28}$ clusters. The relative total energies in $\mathrm{eV}$.

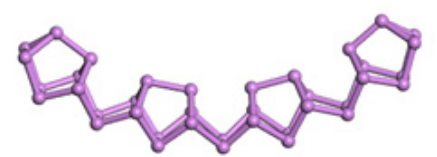

$\mathrm{a}(\mathrm{C} 2 \mathrm{v}, 0.00)$

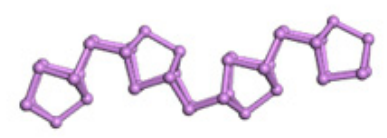

c (Cs, 0.22)

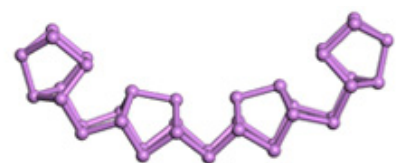

$\mathrm{b}(\mathrm{C} 2 \mathrm{v}, 0.10)$

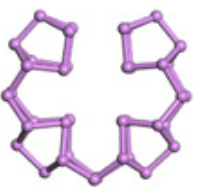

$\mathrm{d}(\mathrm{C} 2 \mathrm{v}, 1.11)$

Figure 5. Lowest-energy and isomorphic structures for $\mathrm{As}_{38}$ clusters. The relative total energies are in $\mathrm{eV}$.

Considering that $\mathrm{As}_{40}$ can form ring and fullerene cage structures, we also studied the structures of $\mathrm{As}_{40}$. The structures we calculated of $\mathrm{As}_{40}$ are listed along with the increase of energy in Figure 6. We found that the lowest energy structure of $\mathrm{As}_{40}$ with $\mathrm{C}_{1}$ symmetry (Figure 6a) and its isomers Figure $6 \mathrm{~b}\left(0.42 \mathrm{eV}\right.$ energy higher) with $\mathrm{C}_{\mathrm{s}}$ symmetry both were one-dimensional chain structures. Three isomers Figure $6 c$,d,e could all be regarded as two-dimensional structures and energetically 
higher than the lowest energy structure a with $0.014 \mathrm{eV} /$ atom, $0.044 \mathrm{eV} /$ atom, and $0.09 \mathrm{eV} /$ atom, respectively. Seemingly stable three-dimensional fullerene cage isomers Figure $6 \mathrm{f}$ with $\mathrm{D}_{5 \mathrm{~d}}$ symmetry and Figure $6 \mathrm{~g}$ with $\mathrm{D}_{5 \mathrm{~d}}$ symmetry were $0.194 \mathrm{eV} /$ atom and $0.226 \mathrm{eV} /$ atom higher in energy than the lowest energy structure.

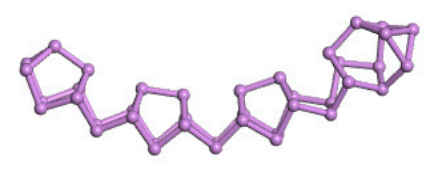

a $(\mathrm{C} 1,0.00)$

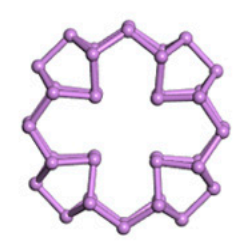

c (D4h, 0.56)

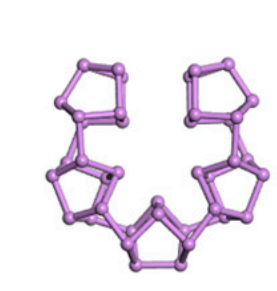

$\mathrm{d}(\mathrm{C} 1,1.77)$

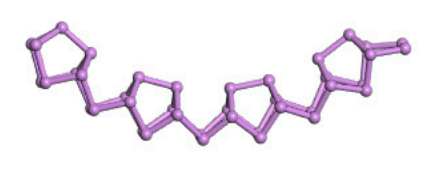

b (Cs, 0.42)

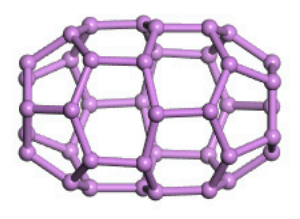

f (D5d, 7.76)

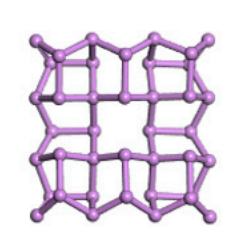

e $\left(\mathrm{C}_{2 \mathrm{v}}, 3.63\right)$

Figure 6. Lowest-energy and isomorphic structures for $\mathrm{As}_{40}$ clusters. The relative total energies in are $\mathrm{eV}$.

Based on the finding above, we could construct the ring structure of an As 180 cluster based on the $\mathrm{As}_{8}$ units and $\mathrm{As}_{2}$ bridge, which is shown in Figure 7. The HOMO-LUMO gap of $\mathrm{As}_{180}$ was $1.868 \mathrm{eV}$ and the binding energy per atom was $-2.901 \mathrm{eV}$.

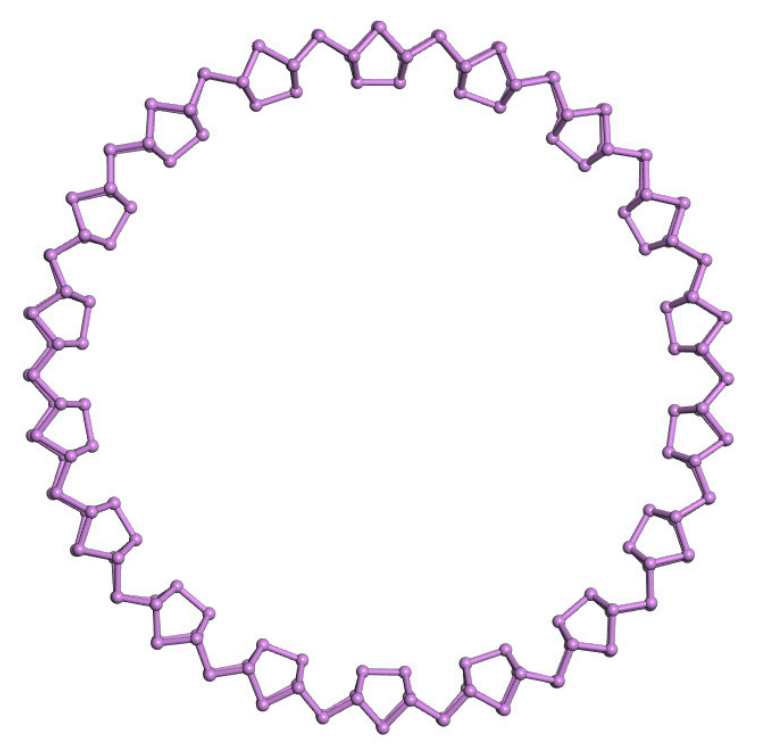

Figure 7. Possible structure for $\mathrm{As}_{180}$ cluster. 


\subsection{Electronic Properties of $A s_{n}$ Clusters}

The binding energy per atom for the ground states of $\mathrm{As}_{n}(n=2-24)$ clusters are shown in Figure $8 \mathrm{a}$. In the size range of $n=12-24$, the binding energy increased smoothly with weak odd-even oscillation properties. This result can be related to the evolution of the ground-state from cage-like structure to cage-link structure at $n=12$. Besides, the binding energy of $\mathrm{As}_{8}$ was a peak value in the small size of $n=3-11$, and this suggests the ground structure of As 8 would be a vital growth unit in larger structures. Our next calculation also proved the conjecture.
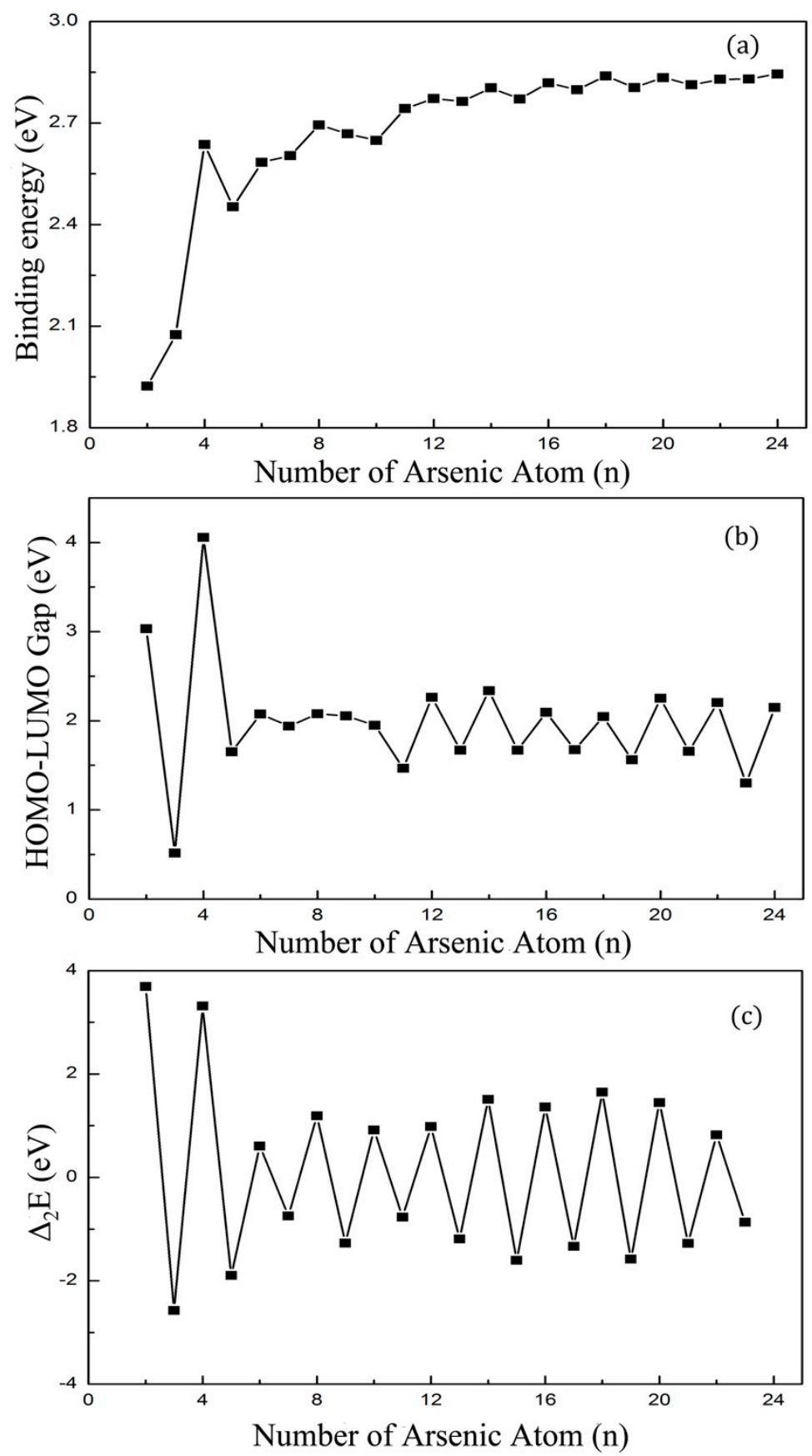

Figure 8. (a) Average binding energies (b) HOMO-LUMO Gaps and (c) second-order difference of cluster energies of $A s_{n}$ clusters. 
In Figure 8b, we present the energy gaps between the highest occupied molecular orbital (HOMO) and lowest unoccupied molecular orbital (LUMO) for the lowest-energy state of $\operatorname{As}_{n}(n=2-24)$ clusters. As is known, the cluster with the larger energy gap is more stable and easier to prepare. As the largest energy gap of $\mathrm{As}_{4}$ is $4.06 \mathrm{eV}$, it is the most prominent species in arsenic vapor, leading to a number of experimental and theoretical studies on $\mathrm{As}_{4}$ clusters. Although the gaps of $\mathrm{As}_{\mathrm{n}}$ clusters from $n=5-10$ change smoothly, we also observe the gap of As 8 is highest locally, which points out that the stability of $\mathrm{As}_{8}$ was higher than the neighboring cluster. The HOMO-LUMO gap was higher for $\operatorname{As}_{n}(n=4,6,8,12,14,16,18,20,22$, and 24) than their adjacent structures. The atoms in these even-numbered sequences were all three-coordination and eight-electron structure. The odd-numbered clusters were unable to achieve this condition, so they were less stable than the odd-numbered species.

In clusters physics, the second-order difference of cluster energy is a more sensitive datum to reflect the stability of clusters. We plotted the second-order difference of cluster energies defined by $\Delta^{2} E=\mathrm{E}(n+1)+\mathrm{E}(n-1)-2 \mathrm{E}(n)$. Figure $8 \mathrm{c}$ describes how the second-order differential energy changed with the increase of atom number and it shows good odd-even oscillation properties. The second-order difference of cluster energies of even-numbered clusters were all higher than their adjacent odd-numbered clusters. Therefore, we could draw the conclusion that even-numbered clusters were more stable than their neighboring odd-numbered clusters. Above all peaks for $\Delta^{2} E$, three local maximum peaks were found at $n=4,8$, and 18 , where $\operatorname{As}_{n}(n=4,8$, and 18) clusters were chemically stable.

\section{Conclusions}

We have adopted the genetic algorithm and all-electron DFT calculations to systematically study the structures and electronic properties of $\mathrm{As}_{\mathrm{n}}(n=2-24)$. The ground-state structures of $A s_{n}$ clusters change from two to three dimensional after $n=3$. Arsenic clusters followed a structural growth pattern starting from $n=8$ and the structures of $\operatorname{As}_{n}(n=9-24)$ clusters could all be regarded as evolving from the ground state structure of an $\mathrm{As}_{8}$ unit and an $\mathrm{As}_{2}$ bridge. The binding energy of $\operatorname{As}_{n}(n=2-24)$ clusters had a periodic step-like behavior, and the size-dependent HOMO-LUMO gap and second-order difference of cluster energies exhibited obvious even-odd alternations with several magic numbers. Based on the growth pattern concluded from small $\mathrm{As}_{\mathrm{n}}$ clusters, the possible superstructures of $\mathrm{As}_{28}, \mathrm{As}_{38}, \mathrm{As}_{40}$, and $\mathrm{As}_{180}$ were discussed.

Supplementary Materials: The following are available online at http://www.mdpi.com/1996-1944/11/9/ 1596/s1, Figure S1: Low energy isomers of $\mathrm{As}_{n}(n=2-24)$ neutral clusters, Figure S2: Low energy isomers of $\mathrm{As}^{+}{ }_{n}(n=2-24)$ cationic clusters, Figure S3: Low energy isomers of $\mathrm{As}_{n}^{-}(n=2-24)$ anionic clusters.

Author Contributions: Conceptualization, B.W. and Q.Z.; Methodology, Q.Z.; Validation, J.Y., Q.Z. and B.W.; Formal Analysis, J.Y.; Investigation, Q.Z.; Resources, J.X. and B.Z.; Data Curation, J.Y. and Q.Z.; Writing-Original Draft Preparation, B.W. and Q.Z.; Writing-Review \& Editing, J.Y. and Q.Z.; Visualization, J.Y., Q.Z. and B.W; Supervision, Q.Z. and B.W.; Project Administration, J.Y. and Q.Z.; Funding Acquisition, J.Y. and Q.Z.

Funding: This work was supported by the NSFC [11474246, 11774178, 11850410442, 11750110415], the Natural Science Foundation of Jiangsu Province [BK20160061].

Conflicts of Interest: The authors declare no conflict of interest. The founding sponsors had no role in the design of the study; in the collection, analyses, or interpretation of data; in the writing of the manuscript, or in the decision to publish the results.

\section{References}

1. Berry, R.S. Clusters of Atoms and Molecules: Theory, Experiment and Clusters of Atoms; Haberland, H., Ed.; Springer Science \& Business Media: Berlin, Germany, 2013; p. 52.

2. Neugebauer, J.; Zywietz, T.; Scheffler, M.; Northrup, J.E.; Van de Walle, C.G. Clean and As-covered zinc-blende GaN (001) surfaces: Novel surface structures and surfactant behavior. Phys. Rev. Lett. 1998, 80, 3097. [CrossRef] 
3. Bernstein, R.W.; Borg, A.; Husby, H.; Fimland, B.O.; Grepstad, J.K. Capping and decapping of MBE grown GaAs (001), $\mathrm{Al}_{0.5} \mathrm{Ga}_{0.5} \mathrm{As}$ (001), and AlAs (001) investigated with ASP, PES, LEED, and RHEED. Appl. Surf. Sci. 1992, 56, 74-80. [CrossRef]

4. Smith, D.L. Thin-Film Deposition: Principles and Practice; McGraw-hill: New York, NJ, USA, 1995; p. 108.

5. Garcia, J.C.; Neri, C.; Massies, J. A comparative study of the interaction kinetics of $\mathrm{As}_{2}$ and $\mathrm{As}_{4}$ molecules with Ga-rich GaAs (001) surfaces. J. Cryst. Growth 1989, 98, 511-518. [CrossRef]

6. Shiraishi, K.; Ito, T. First principles study of arsenic incorporation on a GaAs (001) surface during MBE growth. Surf. Sci. 1996, 357, 451-454. [CrossRef]

7. Wu, B.J.; Mii, Y.J.; Chen, M.; Wang, K.L.; Murray, J.J. Reduced silicon donor incorporation in MBE grown GaAs layers using cracker-generated dimer arsenic. J. Cryst. Growth 1991, 111, 252-259. [CrossRef]

8. Kawanaka, M.; Iguchi, N.; Fujieda, S.; Furukawa, A.; Baba, T. GeAs as a novel arsenic dimer source for n-type doping of Ge grown by molecular beam epitaxy. J. Appl. Phys. 1993, 74, 3886-3889. [CrossRef]

9. Fernandez, R.; Chow, R. Molecular Beam Epitaxy. In Workbook of the Fifth International Conference; Kaare, S., Ed.; The Norwegian Committee on Permafrost: Trondheim, Norway, 1988; p. 584.

10. Duker, A.A.; Carranza, E.J.; Hale, M. Spatial dependency of Buruli ulcer prevalence on arsenic-enriched domains in Amansie West District, Ghana: Implications for arsenic mediation in Mycobacterium ulcerans infection. Int. J. Health Geogr. 2004, 3, 19. [CrossRef] [PubMed]

11. Jay, J.A.; Blute, N.K.; Hemond, H.F.; Durant, J.L. Arsenic-sulfides confound anion exchange resin speciation of aqueous arsenic. Water Res. 2004, 38, 1155-1158. [CrossRef] [PubMed]

12. Wang, L.S.; Niu, B.; Lee, Y.T.; Shirley, D.A.; Ghelichkhani, E.; Grant, E.R. Photoelectron spectroscopy and electronic structure of clusters of the group V elements. III. Tetramers: The ${ }^{2} \mathrm{~T}_{2}$ and ${ }^{2} \mathrm{~A}_{1}$ excited states of $\mathrm{P}_{4}{ }^{+}$, $\mathrm{As}_{4}{ }^{+}$, and $\mathrm{Sb}_{4}{ }^{+}$. J. Chem. Phys. 1990, 93, 6327-6333. [CrossRef]

13. Bennett, S.L.; Margrave, J.L.; Franklin, J.L.; Hudson, J.E. High temperature negative ions: Electron impact of $\mathrm{As}_{4}$ vapor. J. Chem. Phys. 1973, 59, 5814-5819. [CrossRef]

14. Lippa, T.P.; Xu, S.J.; Lyapustina, S.A.; Nilles, J.M.; Bowen, K.H. Photoelectron spectroscopy of $\mathrm{As}^{-}$, $\mathrm{As}^{2-}$, $\mathrm{As}^{3-}, \mathrm{As}^{4-}$, and $\mathrm{As}^{5-}$. J. Chem. Phys. 1998, 109, 10727-10731. [CrossRef]

15. Brumbach, S.B.; Rosenblatt, G.M. In-Cavity Laser Raman Spectroscopy of Vapors at Elevated Temperatures. $\mathrm{As}_{4}$ and $\mathrm{As}_{4} \mathrm{O}_{6}$. J. Chem. Phys. 1972, 56, 3110-3117. [CrossRef]

16. Morino, Y.; Ukaji, T.; Ito, T. Molecular structure determination by gas electron diffraction at high temperatures. I. Arsenic. Bull. Chem. Soc. Jpn. 1966, 39, 64-71. [CrossRef]

17. Zimmerman, J.A.; Bach, S.B.; Watson, C.H.; Eyler, J.R. Ion/molecule reactions of arsenic and phosphorus cluster ions: Ionization potentials and novel reaction pathways. J. Phys. Chem. 1991, 95, 98-104. [CrossRef]

18. Zhao, Y.; Xu, W.; Li, Q.; Xie, Y.; Schaefer, H.F. The arsenic clusters $\mathrm{As}_{\mathrm{n}}(n=1-5)$ and their anions: Structures, thermochemistry, and electron affinities. J. Comp. Chem. 2004, 25, 907-920. [CrossRef] [PubMed]

19. Liang, G.; Wu, Q.; Yang, J. Probing the electronic structure and property of neutral and charged arsenic clusters $\left(\operatorname{As}_{\mathrm{n}}(+1,0,-1), n \leq 8\right)$ using Gaussian-3 theory. J. Phys. Chem. A 2011, 115, 8302-8309. [CrossRef] [PubMed]

20. Guo, L. Evolution of the electronic structure and properties of neutral and charged arsenic clusters. J. Mater. Sci. 2007, 42, 9154-9162. [CrossRef]

21. Bai, X.; Zhang, Q.; Gao, A.; Yang, J. Arsenic clusters $\operatorname{As}_{n}(n=6-16)$ and their anions: Structures, thermochemistry, and electron affinities. Comput. Theor. Chem. 2013, 1009, 94-102. [CrossRef]

22. Zhao, J.; Zhou, X.; Chen, X.; Wang, J.; Jellinek, J. Density-functional study of small and medium-sized As clusters up to $n=28$. Phys. Rev. B. 2006, 73, 115418. [CrossRef]

23. Baruah, T.; Pederson, M.R.; Zope, R.R.; Beltran, M.R. Stability of $\operatorname{As}_{n}[n=4,8,20,28,32,36,60]$ cage structures. Chem. Phys. Lett. 2004, 387, 476-480. [CrossRef]

24. Perdew, J.P.; Burke, K.; Ernzerhof, M. Generalized gradient approximation made simple. Phys. Rev. Lett. 1996, 77, 3865. [CrossRef] [PubMed]

25. Delley, B. DMOL is a density functional theory (DFT) program distributed by Accelrys, Inc. J. Chem. Phys. 1990, 92, 508. [CrossRef]

26. Zhao, J.; Luo, Y.; Wang, G. Tight-binding study of structural and electronic properties of silver clusters. Eur. Phys. J. D 2001, 14, 309-316. [CrossRef]

27. Zhao, J. Density-functional study of structures and electronic properties of Cd clusters. Phys. Rev. A 2001, 64, 043204. [CrossRef] 
28. Zhao, J.; Xie, R.H. Genetic algorithms for the geometry optimization of atomic and molecular clusters. J. Comput. Theor. Nanosci. 2004, 1, 117-131. [CrossRef]

29. Zhao, J.; Shi, R.; Sai, L.; Huang, X.; Su, Y. Comprehensive genetic algorithm for ab initio global optimisation of clusters. Mol. Simul. 2016, 42, 809-819. [CrossRef]

30. Huber, K.-P. Molecular Spectra and Molecular Structure: IV. Constants of Diatomic Molecules; Springer Science \& Business Media: Berlin, Germany, 2013.

Sample Availability: Samples of the compounds are available from the authors.

(C) 2018 by the authors. Licensee MDPI, Basel, Switzerland. This article is an open access article distributed under the terms and conditions of the Creative Commons Attribution (CC BY) license (http://creativecommons.org/licenses/by/4.0/). 